\title{
Análise gráfica de resultados de projetos desenvolvidos por alunos em um curso técnico de design gráfico em São Paulo
}

Maria Beatriz Saraiva Dinelli é designer gráfica formada pela Fundação Armando Álvares Penteado (FAAP), com especialização em design gráfico pelo Istituto Lorenzo de' Medici, Florença, Itália. Mestranda em design pela Faculdade de Arquitetura e Urbanismo da Universidade de São Paulo (FAU-USP), com pesquisa voltada para o ensino de design gráfico em escolas técnicas de São Paulo. <beatrizdinelli@gmail.com> ORCID: 0000-0003-4370-1475
Resumo Este estudo objetivou compreender como projetos escolares de alunos de um curso técnico de design gráfico, em São Paulo, em 2015, poderiam refletir elementos da cultura visual dos discentes. Por meio de pesquisa qualitativa, pretendeu-se mapear componentes de linguagem visual em resultados de projetos de embalagens no Curso Técnico em Comunicação Visual, no Senac-SP, buscando identificar e analisar os elementos da cultura visual expressa nos trabalhos. Para isto, procurou-se sistematizar o corpus, analisar observações de campo, além de elaborar uma matriz de análise gráfica e paramétrica. Nos projetos, percebeu-se exploração relativamente restrita da gama de recursos expressivos do design, com adoção de padrões visuais, em geral, bastante convencionais. Em termos semânticos, parte significativa das composições evocava descontração e informalidade, refletindo experiências pessoais dos alunos. Resultados de tais exercícios parecem, então, espelhar preferências estéticas, repertórios e valores dos discentes, caracterizando, assim, ainda que apenas em parte, a memória gráfica do Curso Técnico em Comunicação Visual, no Senac-SP, em 2015, e a cultura visual idiossincrática daquela geração de alunos, naquele contexto específico.

Palavras chave Pedagogia de design para jovens, ensino técnico de design, ensino de comunicação visual, memória gráfica, cultura visual. 
Luís Cláudio Portugal do Nascimento graduou-se em desenho industrial e comunicação visual na Esdi, Escola Superior de Desenho Industrial, unidade da Uerj, Universidade do Estado do Rio de Janeiro, em 1983. Obteve a "Attestation dÉtude Approfondie", correspondente ao mestrado profissional brasileiro, na área de concepção de produtos novos, na Ensam, École Nationale Supérieure dArts et Métiers, em Paris, em 1987. Doutorou-se em educação de artes, com pesquisa direcionada para o ensino do design, na New York University, em 1997. Possui experiência no magistério de design gráfico e design de produto com ênfase em projeto, metodologia de projeto, metodologia de pesquisa, inovação tecnológica, história, teoria, crítica e ética do design. Atuou na Universidade de Brasília, Esdi-Uerj, Puc-Rio e Unicamp. Atualmente, é professor e pesquisador da Fau-usp, Faculdade de Arquitetura e Urbanismo da Universidade de São Paulo. <claudioportugal@usp.br> ORCID: 0000-0003-4586-1747

\section{Graphic analysis of results of projects developed by students in a graphic design technical course in São Paulo}

Abstract This study aimed to understand how students' school projects in a graphic design technical course in São Paulo in 2015 could reflect elements of the students' visual repertoire. Through qualitative research, visual language components were mapped in the results of packaging projects in the Technical Course in Visual Communication at Senac-SP, seeking to identify and analyze visual culture aspects expressed in the projects. To this end, the corpus was systematized and field observations analyzed, in addition to creating graphic and parametric analysis matrices. A relatively timid exploration of the full range of expressive design resources was noted, such as adoption of quite conventional visual patterns. In semantic terms, a significant portion of the compositions evoked informality, reflecting the students' personal experiences. Results of such exercises seem, then, to mirror students' aesthetic preferences, repertoires and values, thus characterizing, even if only in part, the graphic memory of the Technical Course in Visual Communication at Senac-SP in 2015 and the idiosyncratic visual culture of that generation of students in that specific context.

Keywords Design pedagogy for young people, technical design education, teaching visual communication, graphic memory, visual culture.

\section{Análisis gráfico de resultados de proyectos desarrollados por alumnos en un curso técnico de diseño gráfico en São Paulo}

Resumen El objetivo de la investigación fue comprender cómo los proyectos escolares de alumnos de un curso técnico de diseño gráfico, en São Paulo, durante el 2015, podrían reflejar elementos de la cultura visual de los estudiantes. Por medio de un estudio cualitativo, se pretendió mapear los componentes de lenguaje visual en los resultados de proyectos sobre envases desarrollados en el Curso Técnico en Comunicación Visual, del Senac-SP, buscando identificar y analizar los elementos de la cultura visual expresada en los trabajos. Para ello se buscó sistematizar el corpus y analizar observaciones de campo, además de elaborar una matriz de análisis gráfico y paramétrico. En los proyectos, se percibió un uso relativamente restringido de la gama de recursos expresivos del diseño, con la adopción de patrones visuales, en general, bastante convencionales. En términos semánticos, parte significativa de las composiciones aludía relajación e informalidad, reflejando experiencias personales de los alumnos. Los resultados de estos ejercicios parecen reflejar las preferencias estéticas, los repertorios y los valores de los estudiantes, caracterizando así, aunque sólo en parte, la memoria gráfica del Curso Técnico en Comunicación Visual, del Senac-SP, durante el 2015; y la cultura visual idiosincrática de esta generación de alumnos, en ese contexto específico.

Palabras clave Pedagogía de diseño para jóvenes, enseñanza técnica de diseño, enseñanza de comunicación visual, memoria gráfica, cultura visual. 


\section{Introdução}

Todo redesign indica que certas decisões de projeto, buscando aperfeiçoar aspectos considerados inadequadamente resolvidos em determinado produto já existente foram tomadas. As possibilidades são inúmeras, porém, a estética pura e simples não deve ser parâmetro que norteia seu desenvolvimento. No caso de embalagens, segundo Mestriner (2007), o design precisa transmitir informação básica do que estaria sendo oferecido e ressaltar os atributos complementares do produto, agregando valor a ele. Fatores sociais e culturais de quem e para quem se projeta também influenciam tais resoluções.

Este estudo objetivou ponderar como o projeto gráfico de exercícios refletem uma cultura visual dos alunos sobre design de embalagens no âmbito de um curso técnico de design gráfico para jovens. Assim, por meio de pesquisa qualitativa, pretendeu-se identificar os elementos de linguagem visual em resultados de exercícios práticos de projeto de comunicação visual e inferir sobre a cultura visual expressa nesse conjunto de trabalhos. o corpus para análise foi constituído pelos projetos finais de alunos (representados em pranchas de visualização e arquivos visuais digitais) e pelos relatórios de pesquisa. Esses exercícios fizeram parte da disciplina de design de embalagem denominada Programação Visual de Design Promocional e Marketing Direto, do Curso Técnico em Comunicação Visual, no Serviço Nacional de Aprendizagem Comercial (Senac) de São Paulo, em 2015, buscando-se, assim, caracterizar-se a memória gráfica deste Curso.

Para isto, este estudo se valeu de variados procedimentos, tais como: organizar as peças no conjunto do corpus, analisar os relatórios de estudos de campo procurando identificar o que cada um destacou como importante nas embalagens da categoria do produto escolhido, elaborar uma matriz, por meio da técnica da análise paramétrica (que permitisse visualizar os padrões gerais, as recorrências para posterior análise comparativa), elaborar descrições sistemáticas e análises críticas dessa produção.

Como suporte teórico, foram considerados estudos de Twyman (1979) em linguagem gráfica, Villas-Boas (2009) em análise gráfica, principalmente na diagramação estrutural, Gomes Filho (2009) em elementos de composição visual, Goldsmith (1980) na análise das imagens do ponto de vista da sintática e semântica, Negrão e Camargo (2008) em linguagem das cores, linguagem tipográfica e leitura visual, Aragão (2011) em aspectos de singularidade e universalidade em diferentes composições visuais dadas, Silva e Farias (2005) em tipografia, Meneses (2003) em visualidade, cultura visual e no papel de diferentes grupos de indivíduos (tais como alunos) no conjunto da sociedade maior e Queluz (2008) em questões de design e identidade. 


\section{Curso técnico de design gráfico no Senac São Paulo}

O mercado da comunicação visual torna-se cada vez mais competitivo em vista das grandes transformações advindas dos sistemas e processos digitais de pré-impressão, impressão e pós-impressão. Todos os setores responsáveis pelo planejamento, produção e reprodução de imagens sobre suportes físicos foram afetados pelas mudanças das novas tecnologias. Para desenvolver essas novas competências, o profissional que atua nos vários setores de produção de impressos necessita de uma formação técnica polivalente, destinada, principalmente, aos cinco setores de atuação, denominados: editorial, institucional, publicitário, promocional e marketing direto (SENAC, 2010).

O curso técnico de design gráfico ofertado no Senac São Paulo, denominado Técnico em Comunicação Visual, no ano de 2015 era estruturado em cinco módulos: Programação Visual Gráfica, Programação Visual de Design Institucional, Programação Visual de Design Editorial e Publicitário, Programação Visual de Design Promocional e Marketing Direto e Gestão Empreendedora para Comunicação, Arte e Design. As situações de aprendizagem, então previstas para cada módulo, tinham como eixo condutor um projeto que considerava contextos similares àqueles encontrados nas condições reais de trabalho, estimulando a participação ativa dos alunos na busca de soluções para os desafios.

Em 2015, havia encontros cinco vezes por semana, com quatro horas diárias. 0 perfil dos estudantes era o de jovens, entre 16 e 22 anos, cursando o segundo ou terceiro ano do ensino médio da rede pública de São Paulo ou que o haviam finalizado há menos de cinco anos. A maior parte residia com os pais na periferia de São Paulo e seus gastos eram financiados pela família.

Proposta de reprojeto de design de embalagem

A disciplina "Programação Visual de Design Promocional e de Marketing Direto", correspondente ao quarto módulo do Curso, por demandar conhecimentos e habilidades mais avançadas de design gráfico, foi realizada no último período da grade curricular, com duração de 190 horas. Essa disciplina foi dividida em duas fases: a primeira visava à construção de conhecimento básico do design de embalagem para o desenvolvimento de competências, alternando aulas teóricas e exercícios práticos, que subsidiaria a elaboração do projeto final, na segunda fase.

Aspectos teóricos abordaram componentes históricos, tipos de embalagem, conceitos compositivos, linguagem das formas e das cores, além de metodologia de projeto de design de embalagem. Desde o princípio, foi proposto aos alunos coletar embalagens para compor um repertório de alternativas existentes, posteriormente usadas para análises gráficas e de 
processos de impressão. Além disso, pesquisaram, na internet, leis e normas que incidiam sobre rótulos de embalagens alimentícias e de higiene pessoal. Executaram planificações, desenhos de faca de corte de cartonados e representações tridimensionais de diversas embalagens em aplicativos de desenho vetorial e de manipulação de imagens.

Com base nessas atividades, passou-se à fase de desenvolvimento do projeto, elaborado individualmente, cuja proposta era o redesign de uma embalagem de papel cartonado de produtos comercializados em supermercados (de mercearia, bebida, higiene pessoal ou limpeza), apresentando layouts e arte da faca de corte, bem como produção de peças gráficas para promoção do produto no ponto de venda. Para isso, o projeto foi dividido em quatro etapas: Planejamento, Forma, Entrega e Apresentação. A etapa "Planejamento" compreendia definir o problema do produto e peças para ponto de venda, pesquisar a concorrência do produto nos supermercados, analisar características gráficas do projeto da embalagem, elaborar documento de texto com justificativas, conceito, formato, identidade visual, paleta de cores e tipografia das peças. Na etapa "Forma", deveriam produzir layouts e artes finais dos elementos visuais da embalagem e das peças promocionais, com formato compatível para impressão gráfica, seguida das etapas "Entrega" e "Apresentação".

\section{As soluções adotadas na organização dos elementos visuais}

Ao final da disciplina foram apresentados 20 projetos de embalagens, são eles: Casino, chocolate; Fibra mais, cereal integral; Leite condensado Mococa; Bon o bon, bombons sortidos; Ariel, sabão em pó; Sorriso, gel dental; Purity, néctar de fruta; Tirol, leite; Toddynho, achocolatado; chá Doce carinho, Dr Oetker; Native, café orgânico; Lowçugar plus, multiadoçante; Cor \& Tom, coloração creme; Coco do Vale, água de coco; Harpic power plus, limpador sanitário; Bolo de chocolate Dr Oetker; Molho com atum sabor tomate, Gomes da Costa; Bananada cremosa, Flormel; 3 corações, filtro de papel; Hydrata, sabonete cremoso.

Para proceder à análise gráfica dos resultados de reprojeto de embalagens, tomou-se como base a distinção de Villas-Boas (2009) dos elementos formais em aqueles de ordem estética e aqueles de ordem técnica: o termo "estética" correspondendo ao que realmente é visto na face frontal da embalagem e "técnica" referente ao que não é visto, mas que se encontra por trás da organização do layout. Os elementos estético-formais foram subdivididos em componentes textuais (tipografia do produto, tipografia da designação do tipo de produto e tipografia das demais informações) e componentes não textuais (imagem principal, posição da imagem, cor da imagem, elementos abstratos e cor dos elementos). Os elementos técnico-formais, por sua vez, foram subdivididos em princípios projetuais (har- 
monia, síntese, balanceamento e movimento) e dispositivos de composição (estrutura, centramento e eixo). Para Twyman (1982), a linguagem visual é dividida em não gráfica e gráfica. A gráfica, por seu turno, está subdividida em pictórica, esquemática (correspondendo aos componentes não textuais de Villas-Boas) e verbal (equivalendo aos componentes textuais).

As faces frontais das embalagens apresentam, como já mencionado, três componentes textuais principais: logotipo do produto, logotipo da designação do tipo de produto e tipografia das demais informações textuais. o logotipo do produto é o componente textual com maior destaque, tanto em relação às suas características visuais quanto à sua dimensão. Cerca de metade dos trabalhos apresenta logotipos em tipografias sem serifa (Figura 1), sendo cinco sem serifa "orgânico" (Native café orgânico, Lowçugar plus multiadoçante, Cor\&tom, Bon o bon e Ariel), duas sem serifa "emulativa" (Sorriso e Purity), uma sem serifa "lineal neo-grotesca" (Leite condensado Mococa) e uma sem serifa "geométrica" (Fibra mais) (SILVA; FARIAS, 2005). Número considerável de logotipos em tipografia "fantasia" também foi identificado (Coco do Vale, Bananada cremosa, Leite Tirol, Toddynho, Harpic e Chá doce carinho) (Figura 2). Em geral, os logotipos se apresentam com tipografia em negrito, em caixa alta ou caixa alta e baixa, posicionados na totalidade na parte superior da face frontal da embalagem, e parte significativa centralizada na largura.

Em relação ao logotipo da designação do tipo do produto, a maior parte optou por tipografias sem serifa, sendo cinco "lineal neo-grotesca", cinco "lineal geométrica", três "humanista", uma "curvi-linear", e dois "orgânico". Apenas duas "escritural" e uma "fantasia". Tais logotipos se apresentam com tipografia em negrito ou regular, em caixa alta ou caixa alta e baixa.

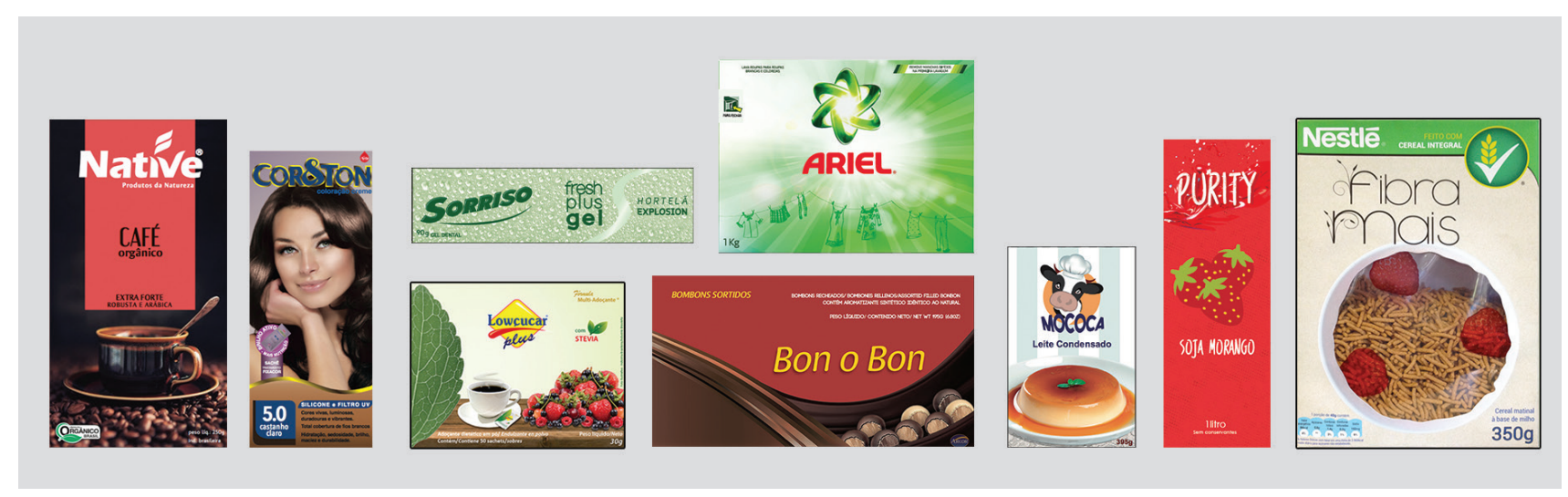

Fig 1. Tipografias sem serifa do logotipo do produto

Fonte: Acervo de Maria Beatriz S. Dinelli, 2018 
As demais informações textuais (tais como: diferencial do produto, peso e quantidade) aparecem majoritariamente numa tipografia sem serifa, "lineal neo-grotesca", em peso regular, escritas em caixa-alta ou caixa-alta e baixa, posicionadas na parte inferior da face frontal. A indicação da quantidade, em muitos casos, mostra-se destacada, em corpo maior.

A totalidade das embalagens, em sua face frontal, apresenta um elemento pictórico principal ou uma imagem composta por vários elementos, compondo uma cena, que, semanticamente, numa relação de literalidade, relaciona-se com o logotipo do produto: por exemplo, a embalagem de Bon o bon é composta visualmente com imagens de bombons. Da mesma forma em Native café orgânico, Coco do vale, Bolo chocolate Dr Oetker, Filtro de papel 3 corações (Figura 3). Raras são as incidências de relações metafóricas, como em "Doce carinho", representado por desenhos de "bichinhos fofinhos". Esses paralelos com texto, conforme Goldsmith (1979), seriam propostos como o fator que promoveria verbalização do processo de tradução.

Fig 2. Tipografias "Fantasia" do logotipo do produto | Fonte: Acervo de Maria Beatriz S. Dinelli, 2018
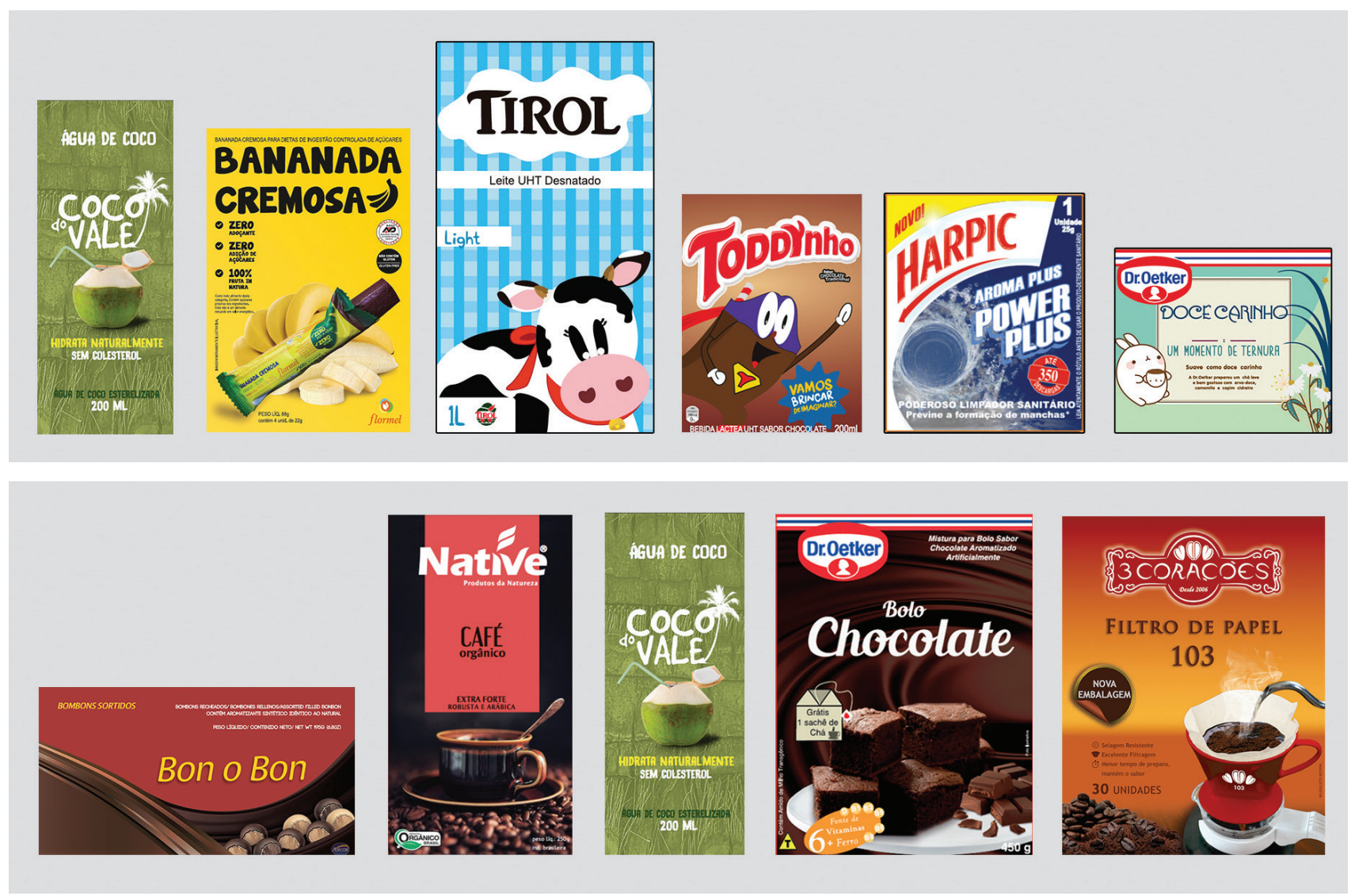

Fig 3. Tipografias sem serifa do logotipo do produto

Fonte: Acervo de Maria Beatriz S. Dinelli, 2018 
A grande maioria dos elementos pictóricos principais são imagens fotográficas, sendo que todas as embalagens que se utilizaram de desenhos vetoriais eram representações figurativas - três de personagens, direcionadas ao público infantil, como em Toddynho, Chá doce carinho $e$ Leite Tirol. (Figura 4). A unidade semântica é percebida na totalidade das imagens fotográficas por meio da clara e imediata identificação representacional, porém, tal clareza de reconhecimento não é evidenciada nos desenhos vetoriais de personagens.

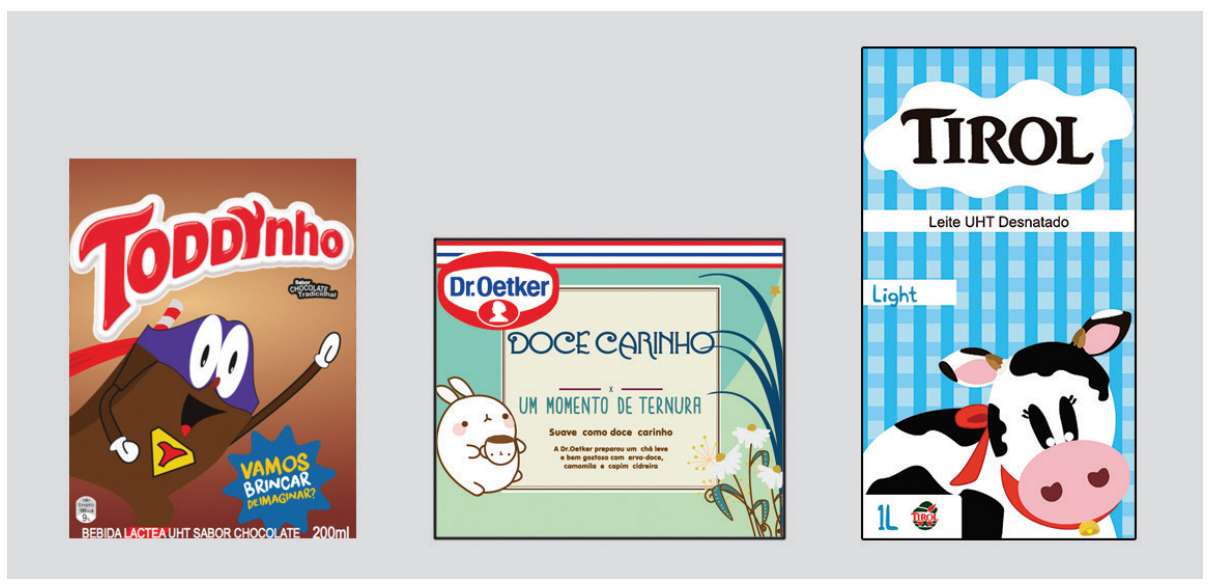

Fig 4. Imagens vetoriais de personagens direcionadas ao público infantil Fonte: Acervo de Maria Beatriz S. Dinelli, 2018

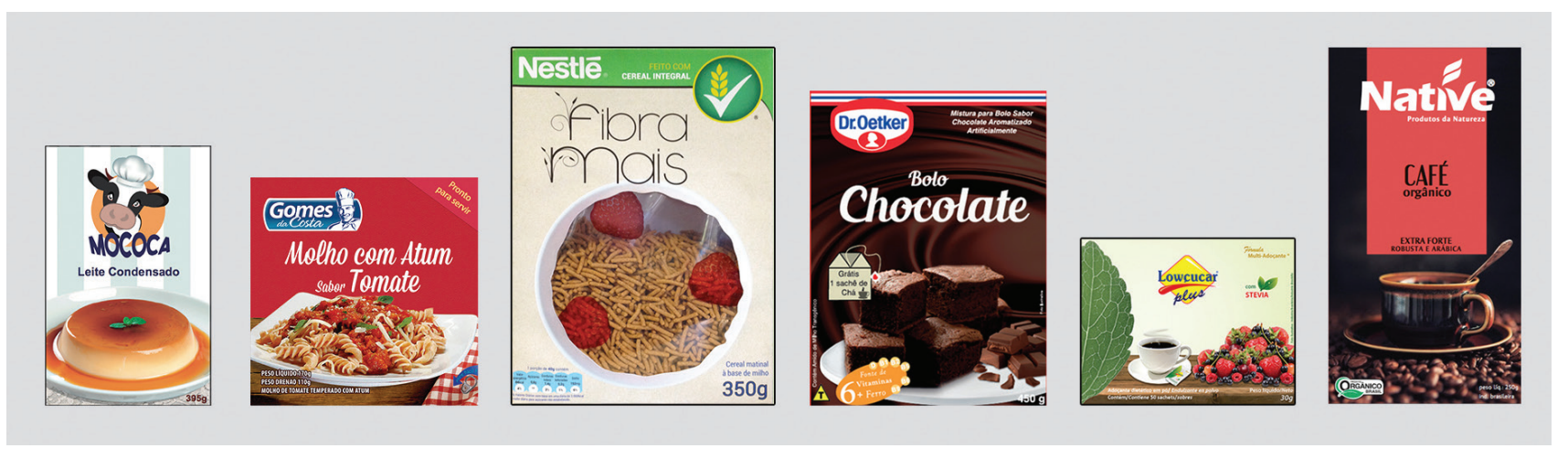

Fig 5. Representação de alimentos

em pratos ou xícaras| Fonte: Acervo de Maria Beatriz S. Dinelli, 2018

Em geral, as imagens apresentam boa unidade sintática. Algumas representações são mais simples, como em Café orgânico Native, Molho de atum sabor tomate, Fibra mais, Putity néctar de fruta, Coco do vale e Leite condensado Mococa. Já outras são composições mais elaboradas, como: Chocolate Casino, Bon o bon, Lowsugar multiadoçante, Bananada cremosa e Filtro de papel 3 corações.

Os elementos pictóricos relacionados aos alimentos são, em geral, representados por inteiro, em pratos (Leite condensado Mococa, Molho com atum sabor tomate, Fibra mais e Bolo chocolate Dr Oetker) ou em xícaras (Lowçugar plus multiadoçante e Native café orgânico) (Figura 5). A maior parte das embalagens apresenta a imagem principal centralizada na porção inferior da diagramação. 
Quanto aos elementos abstratos, o splash, aparece em formatos diversificados em metade dos projetos, proporcionando, segundo Mestriner (2007), vida e vibração à embalagem, destacando os atributos principais do produto $\mathrm{e}$ seu apelo de vendas, como, por exemplo, em Cor\&Tom, Filtro de papel 3 corações, Coco do vale, Bolo de chocolate, Fibra mais, Harpic, Ariel, Toddynho, Molho com atum sabor tomate e Bananada cremosa (Figura 6). Os demais elementos identificados foram: retângulos - usados como elemento integrador entre logotipo e imagem (Chocolate Casino e Café orgânico Native), faixa em formato orgânico - que promoveu ritmo e continuidade entre todos os planos em Cor\&Tom e faixa em formato de "S" - em Sorriso, como divisor de áreas.

Boa parte das imagens apresenta cores saturadas, mas também cores frias, como os azuis e verdes. A incidência de cores saturadas é maior nos demais elementos, aí inclusos os logotipos, formas geométricas, splashs, fundos chapados ou dégradé.
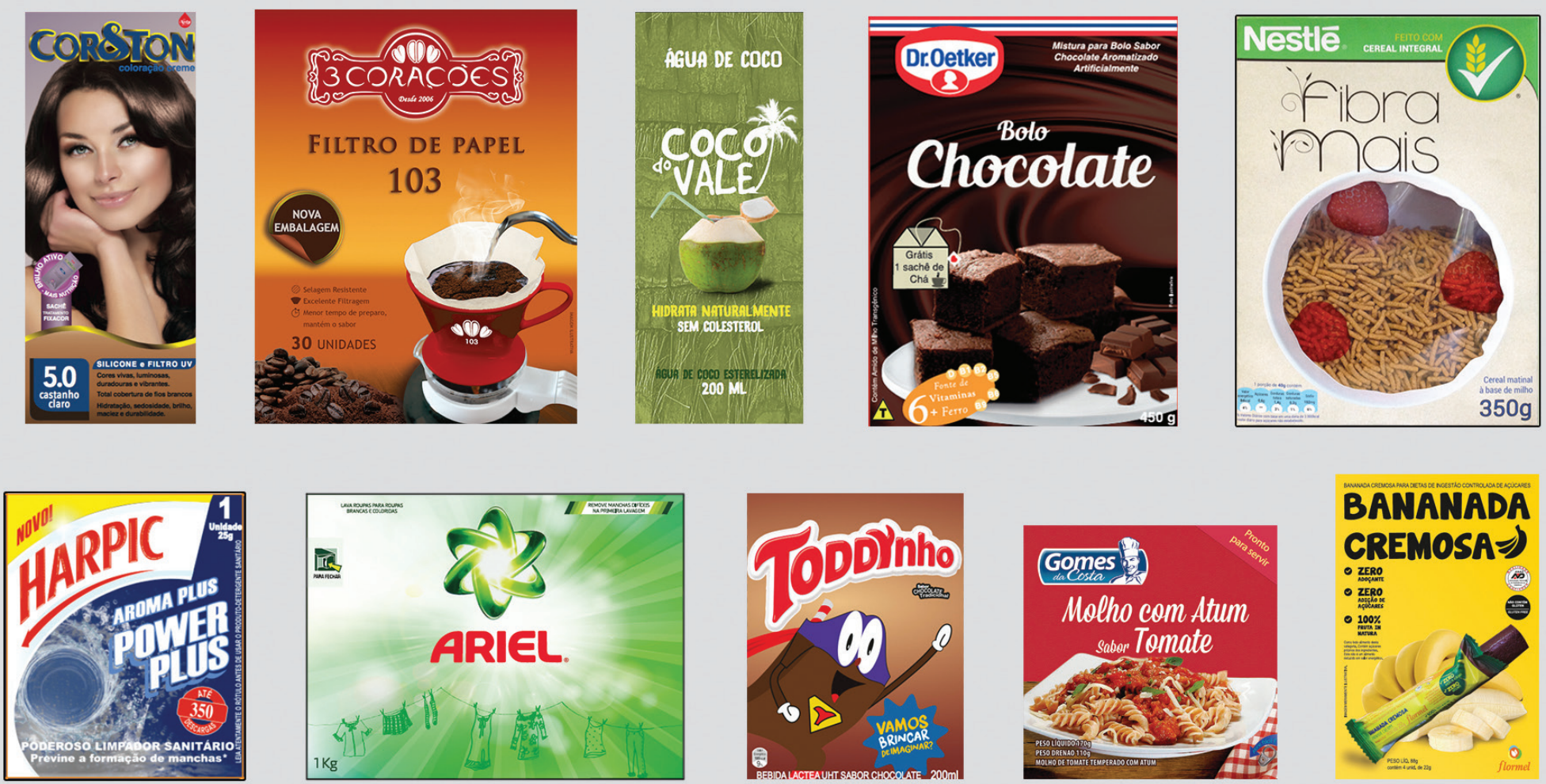

Fig 6. Ênfase com splashs

Fonte: Acervo de Maria Beatriz S.

Dinelli, 2018

Com respeito dos dispositivos de composição, a "estrutura" da face frontal das embalagens, de modo geral, apresenta malha gráfica não explícita, com os elementos distribuídos em seu eixo central e logotipo do produto no centro ótico da diagramação. 
Quanto aos princípios projetuais, segundo Villas-Boas (2009) e Gomes Filho (2009), a "harmonia" é conferida pela lógica na organização coerente de todos seus elementos, possibilitando uma leitura simples e clara. Na maior parte dos casos, percebe-se harmonia por ordem na relação entre imagem principal, logotipos e cores utilizadas.

Sendo projeto de embalagem - que requer leitura rápida - a informação deve ser transmitida com um mínimo de elementos visuais. Deste modo, o princípio da "síntese" é notado por meio da disposição dos elementos básicos, em geral, na seguinte ordem, de cima para baixo: logotipo, texto, imagem ou logotipo, imagem e texto.

Já o "balanceamento", segundo Villas-Boas (2007), corresponde à organização dos elementos visuais na superfície de modo objetivo (equilíbrio simétrico) ou subjetivo, pela percepção de seus "pesos" (equilíbrio assimétrico). Boa parte das embalagens apresenta equilíbrio axial simétrico (Figura 7). Negrão e Camargo (2008) acrescentam o equilíbrio oculto, no qual não se percebem eixos explícitos, mas um centro gravitacional implícito (Bon o bon e Sorriso) e o equilíbrio radial, cuja atração é determinada pela rotação de um ponto no espaço e sua expansão no campo visual em forma radial e progressiva, por exemplo, em Toddynho e Harpic (Figura 8). Assim, o princípio do "movimento", fortemente relacionado ao eixo compositivo adotado, é especialmente percebido em embalagens com predomínio de composições em equilíbrio radial.
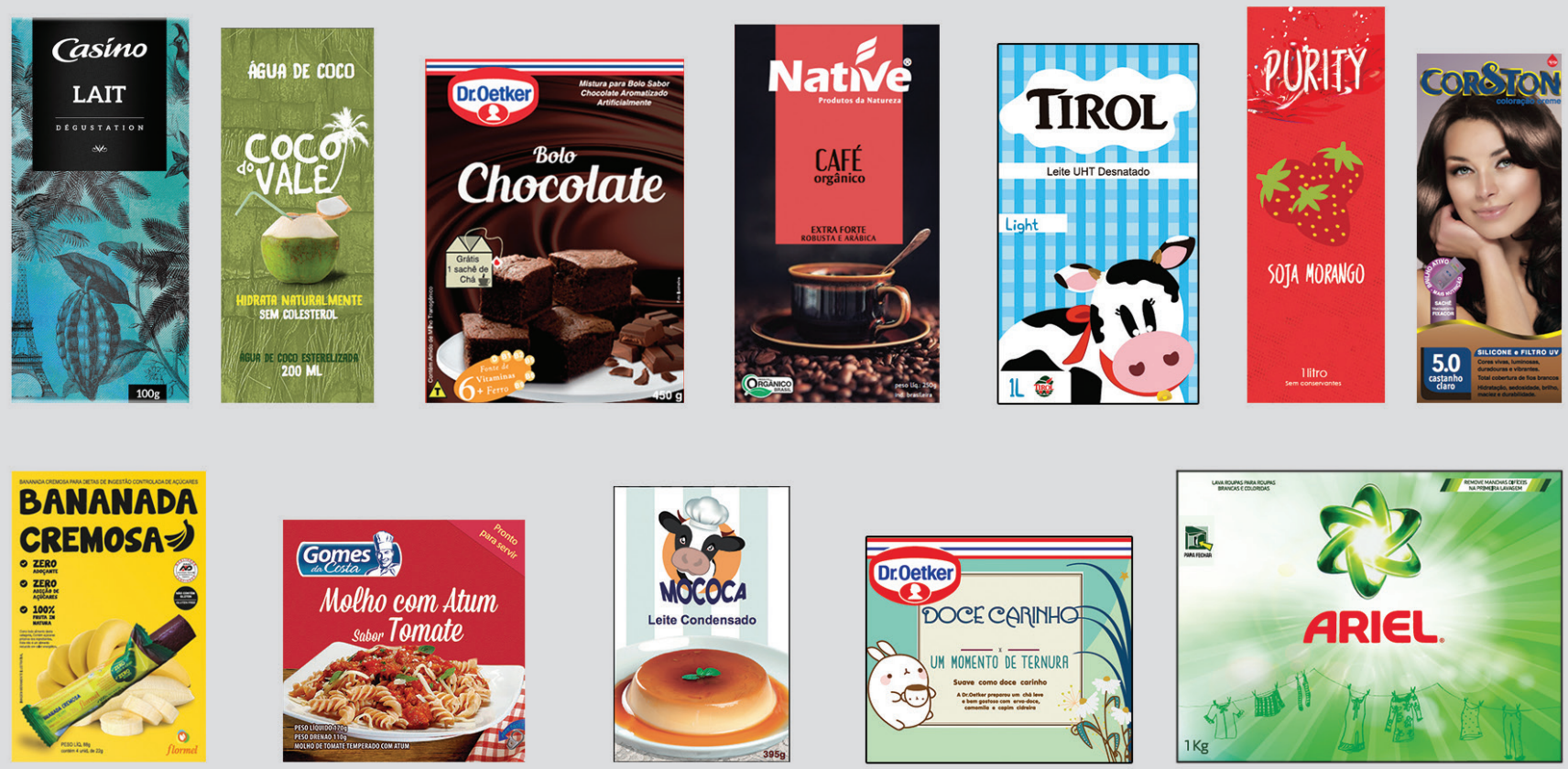

Fig 7. Composições em equilíbrio visual simétrico

Fonte: Acervo de Maria Beatriz S. Dinelli, 2018 
Para apoiar a leitura visual da face frontal das embalagens, adotaram-se as leis da Gestalt e as categorias conceituais. O princípio da "unificação" da forma é notado em boa parte das composições, uma vez que a maioria apresenta equilíbrio visual simétrico e harmonia por coerência (do estilo formal entre tipografia, imagens e cores). Em referência às categorias conceituais, a "exageração dimensional" e/ou "de peso" é evidenciada no logotipo do produto, na imagem principal ou em ambos. A "ênfase" igualmente é percebida por meio do contraste tonal cromático em grande parte das composições, sobretudo na relação do logotipo do produto e fundo, seja liso ou fotográfico.

O "ruído visual", isto é, interferência na harmonia ou no equilíbrio visual do conjunto, é observado em algumas embalagens, por exemplo, no posicionamento do texto do splash em sentido diagonal em Molho de atum sabor tomate e, também, na ilustração do modo de fechamento, posicionado na face frontal, em Ariel. De modo semelhante, a "exageração" na quantidade de splashs em Bolo chocolate Dr Oetker contribuiu para desarmonia do conjunto. Já o ruído visual positivo é notado em Cor\&Tom por meio de seu splash, que cria um ponto de interesse para um sachê no interior da embalagem (Figura 9). De modo geral, a organização visual das faces frontais das emba-

Fig 8. Composições em equilíbrio assimétrico (as da esquerda) e radial (as da direita) | Fonte: Acervo de Maria Beatriz S. Dinelli, 2018 lagens apresenta boa ou alta pregnância pela organização formal, simples, harmoniosa e por proporcionar facilidade de leitura visual.

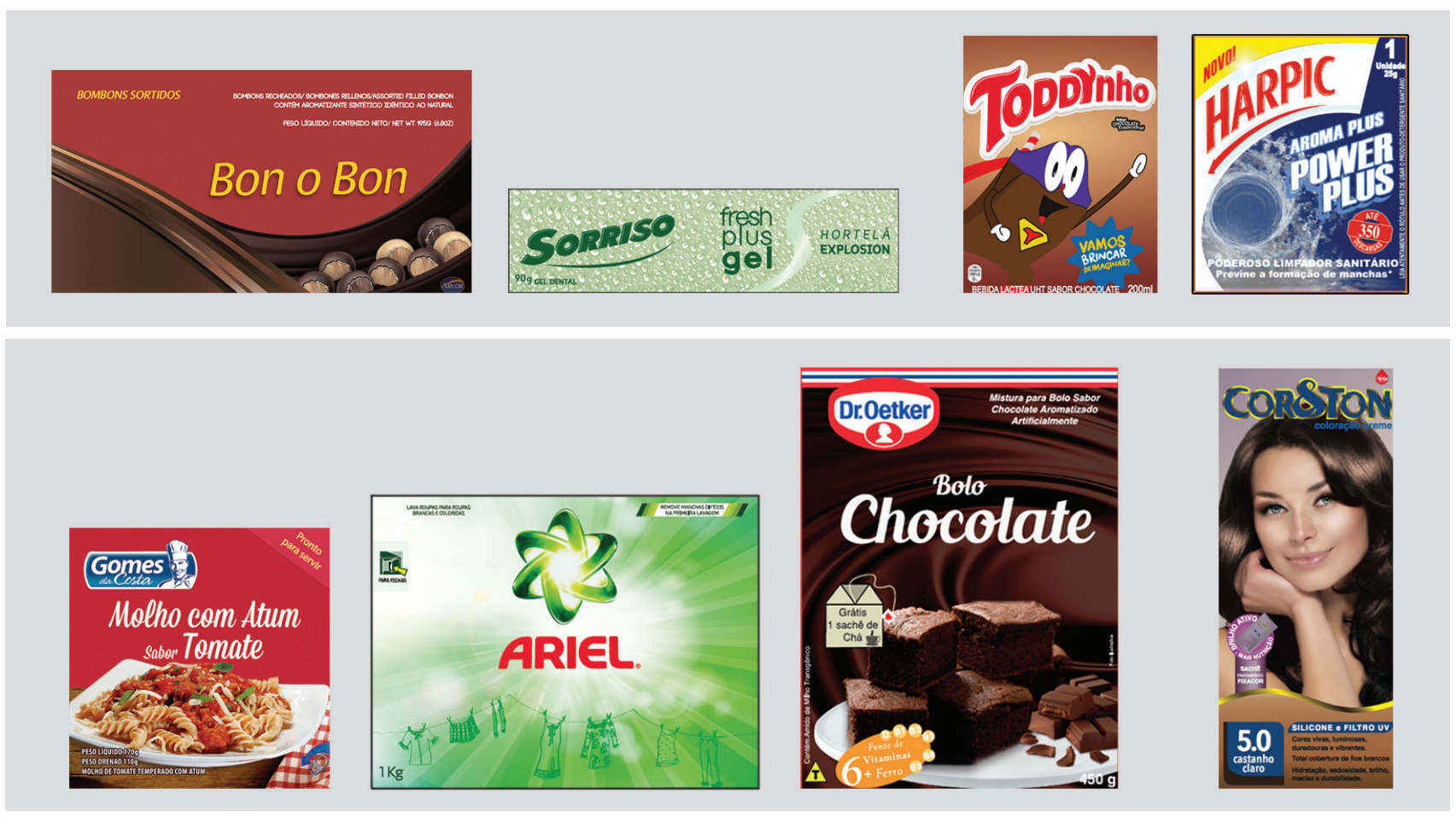

Fig 9. Ruído visual negativo (as três embalagens à esquerda) e ruído visual positivo (embalagem à direta) | Fonte: Acervo de Maria Beatriz S. Dinelli, 2018 


\section{Resultados}

Dos 20 projetos de alunos considerados nesta pesquisa, notou-se relativamente restrita exploração da gama de recursos expressivos do design, além de preferência por composições mais simples, diretas, centralizadas e estáticas, com baixa densidade de informações, compostas por logotipo, imagem e texto. Poucos projetos, por exemplo, tiraram partido da tridimensionalidade da embalagem, como volume no espaço dotado de várias faces articuláveis entre si.

Número significativo de alunos não optou pelo redesenho do logotipo da empresa, provavelmente por julgar que eventuais alterações na identidade visual das marcas seria extensível a toda sua gama de produtos. Por outro lado, a maioria dos projetos incluiu o redesenho do logotipo do produto. Porém, a composição do logotipo (na horizontal, vertical ou em sentido radial) foi preservada em expressivo número de casos, com exceção de Coco do vale, Fibra mais e Purity néctar de fruta, categorias estas que privilegiam logotipos na diagonal ou em sentido radial. Não por acaso, a variação mais significativa em termos de "movimento" ocorreu nestas três embalagens: de composições tradicionalmente dinâmicas para estáticas. Parece que os alunos não se aperceberam, possivelmente pela pouca experiência, de que o equilíbrio não requer necessariamente simetria, uma vez que composições assimétricas podem ser harmônicas.

Metade dos logotipos dos produtos acompanhou as tipografias da categoria do produto e do mercado e a grande maioria manteve o destaque com tipos em negrito. A tipografia das demais informações seguiu a categoria do produto e do mercado - tipo simples, sem serifa, lineal neo-grotesca, em negrito ou regular, em caixa alta ou em caixa alta e baixa, em corpo reduzido, possivelmente visando maior ênfase a informações consideradas mais importantes, como no logotipo do produto e no logotipo do tipo de produto.

Todas as imagens empregadas nos projetos foram alteradas, com predomínio de reproduções fotográficas de composições clássicas, em termos de representação, cores e composição, sugerindo propensão a retratar a realidade de modo verossímil, com mínimo de ambiguidade acresci$\mathrm{da}$, eventualmente, de aspectos de plasticidade e empatia suscitados pelo realismo da linguagem fotográfica em imagens agradáveis e convidativas. Além disso, imagens mais elaboradas requerem um repertório maior. De modo geral, as representações e cores das imagens seguiram a categoria do produto e do mercado, bem como as cores dos demais elementos, inclusos logotipos e fundos.

Número significativo dos projetos baseou-se em diagramação centralizada. Poucos apresentaram acentuada assimetria. A maior parte dos alunos adotou padrões relativamente convencionais, não havendo trabalhos que ousassem propor composições visuais desestruturadas em relação ao então praticado profissionalmente. 


\section{Considerações finais}

A preferência por composições mais estáticas parece sugerir que esses jovens, ainda em formação, tanto emocional quanto em termos de habilidades e competências, optaram por estratégias de resoluções de problemas de design mais ágeis e tecnicamente mais fáceis, que os mantivessem em suas "zonas de conforto".

Quanto a aspectos semânticos, que, de acordo com Goldsmith (1980) implicam interpretação e podem depender de fatores culturais, sociais e, mesmo, desenvolvimentais, a maioria das composições não evoca seriedade, refinamento, algo clássico, mas descontração, informalidade, popular, parecendo refletir o modo de vida de uma geração que frequenta supermercados, shoppings, "baladas", ambientes que, normalmente, não fomentem práticas analíticas. Além disto, possivelmente pela idade reduzida e, talvez, pouca oportunidade, estes projetos, em geral, não denotavam apuro formal. Tais aspectos sugerem eventual tendência, ainda a ser confirmada por estudos complementares sobre este mesmo tema, já que, como especula Queluz (2008) a reflexão das experiências de vida possibilitaria compreender aspectos da cultura material e do consumo, além de perceber processos de construção de identidades.

Revelou-se também importante, segundo Meneses (2003), considerar as fontes visuais, além de como documentos, também como componentes da diversidade do próprio jogo social, já que resultados do exercício de redesign de embalagens em que este estudo se baseou refletem preferências estéticas, repertórios e valores de alunos do Curso Técnico em Comunicação Visual do Senac-SP, em 2015. Constitui-se, deste modo, em parte da memória gráfica do Curso, caracterizando, em alguma medida, a cultura visual local e idiossincrática daquela geração de alunos, naquele contexto específico. Espera-se, quanto a isto, haver contribuído para registro da história do ensino de design gráfico em cursos técnicos de São Paulo e, de modo menos direto, também no país. 


\section{Referências}

ARAGÃO, Isabella. O plural e o singular nas composições visuais dos rótulos de bebida. In: CAMPELLO, Silvio \& ARAGÃO, Isabella (eds.) Imagens comerciais de Pernambuco: ensaios sobre os efêmeros da Guaianases, p. 93-113. Recife: Néctar, 2011.

GOLDSMITH, E. Comprehensibility of illustration: an analytical model. In: Information Design Journal, v. 1, n. 3 p. 204-213, 1980. Disponível em: https://www.scribd.com/document/ 133830612/Evelyn-Goldsmith-Comprehensibility-of-Illustration. Acesso em: 3 set. 2018.

GOMES FILHO, João. Gestalt do objeto: sistema de leitura visual da forma. 9.ed. São Paulo: Escrituras Editora, 2009.

MENESES, Ulpiano B. Fontes visuais, cultura visual, história visual. Balanço provisório, propostas cautelares. In: Revista Brasileira de História, v. 23, n. 45, p. 11-36. 2003. Disponível em: <http://www.scielo.br/pdf/rbh/v23n45/16519.pdf>. Acesso em: out. 2018.

MESTRINER, Fabio. Design de embalagem: curso básico. 2.ed. São Paulo: Pearson Makron Brooks, 2007.

NEGRÃO, Celso; CAMARGO, Eleida. Design de embalagem: do marketing à produção. São Paulo: Novatec, 2008.

QUELUZ, Marilda Lopes Pinheiro (Org.). Questões pontuais sobre design e Identidade. In. Design \& Identidade, v.2, p. 13-32 Curitiba: Editora Peregrina, 2008.

SENAC. Plano de curso. Disponível em: <http://www.sp.senac.br/downloads/ComVis>. Acesso em: mai. 2018.

SILVA, Fabio Luiz Carneiro Mourilhe; FARIAS, Priscila Lena. 2005. Um panorama das classificações tipográficas. In: Estudos em Design, v. 11, nº 2, p. 67-81. Disponível em: <http:// www.arcomodular.com.br/portugues/uploads/File/SILVA_FARIAS-PanoramaClassif.pdf>. Acesso em: set. 2018.

TWYMAN, Michael. A schema for the study of graphic language. In: KOLERS, Paul; WROLSTAD, Merald \& BOUMA, Herman (Eds.). Processing of visible language. New York: Plenum Press, v.1, p. 117-150, 1979.

VILLAS-BOAS, André. Sobre análise gráfica, ou algumas estratégias didáticas para a difusão de um design crítico. In: Arcos Design 5, p. 2-17, 2009. <https://edisciplinas.usp.br/pluginfile.php/ 4616123/mod_resource/content/1/VILLAS-BOAS\%202009\%20an\%C3\%A1lise\%20 grafica.pdf>. Acesso em: ago. 2018. 